\title{
A EXPERIÊNCIA DE UMA DISCIPLINA EXTENSIONISTA DO CURSO DE ODONTOLOGIA DURANTE A PANDEMIA DA COVID-19 ${ }^{1}$
}

\section{THE EXPERIENCE OF AN EXTENSIONIST ASSIGNMENT OF THE DENTISTRY COURSE DURING THE COVID-19 PANDEMIC}

\author{
Nathalia Lucca², Gabriela Rossini Dutra ${ }^{3}$, Letícia Dias Machado ${ }^{3}$, \\ Débora Martini Dalpian ${ }^{5}$ e Aline Krüger Batista ${ }^{4}$
}

\section{RESUMO}

Em atividades extensionistas, o compartilhamento de conhecimentos é essencial para mudar hábitos. O objetivo deste trabalho é relatar a experiência de acadêmicas em uma disciplina extensionista do curso de odontologia da Universidade Franciscana-Santa Maria/RS, durante a retomada das atividades práticas na pandemia da COVID-19. A metodologia utilizada nesta disciplina extensionista foi a Espiral Construtivista, uma metodologia ativa de ensino-aprendizado. As atividades de extensão relatadas ocorreram de setembro a dezembro de 2020, durante o período de retomada das atividades práticas na pandemia da COVID-19. Após conhecer a forma que as crianças vivem, como se relacionam e estabelecer as questões problemas, foram propostas soluções previamente planejadas dentro de cada realidade. As necessidades estavam relacionadas principalmente a doença cárie e periodontal. A vivência nesta disciplina foi ao mesmo tempo uma oportunidade de aprendizado e uma experiência construtiva baseada em resiliência e humanização, de diálogos, construção de vínculo, possibilidade de trocas e nos permitiu ajudar a criança a devolver a autonomia do cuidado.

Palavras-chave: Serviços de Saúde em Universidades; Odontologia Comunitária; COVID-19.

\section{ABSTRACT}

In extension activities, knowledge sharing is essential to change habits. The objective of this work is to report the experience of academics in an extension discipline of the dentistry course at Universidade FranciscanaSanta Maria/RS during the resumption of practical activities in the COVID-19 pandemic. The methodology used in this extension discipline was the Constructivist Spiral, an active teaching-learning methodology. The outreach activities reported took place from September to December 2020, during the period of resumption of practical activities in the COVID-19 pandemic. After getting to know the way children live, how they relate to each other and establish the issues and problems, previously planned solutions were proposed within each reality. The needs were mainly related to caries and periodontal disease. The experience in this discipline was at the same time an opportunity for learning and a constructive experience based on resilience and humanization, dialogues, building bonds, the possibility of exchanges, and allowed us to help the child to return the autonomy of care.

Keywords: Student Health Services; Community Dentistry; COVID-19.

\footnotetext{
1 Relato de experiência.

2 Autora. Acadêmica do curso de Odontologia da Universidade Franciscana - Santa Maria/RS. E-mail: nathalia.lucca@ufn.edu.br 3 Coautor. Acadêmicas do curso de Odontologia da Universidade Franciscana - Santa Maria/RS. E-mail: gabriela.dutra@ ufn.edu.br; leticiamachado@ufn.edu.br; deboradalpian@ufn.edu.br 4 Orientador. Docente do curso de Odontologia da Universidade Franciscana - Santa Maria/RS. E-mail: aline.kruger@, prof.ufn.edu.br
} 


\section{INTRODUÇÃO}

Em atividades extensionistas, o compartilhamento de conhecimentos é essencial para mudar hábitos. Uma fase importante para realizar esta intervenção é na infância, pois é quando se constrói os cuidados com a saúde baseado em estilos de vida saudáveis ou não, que serão consolidados na fase adulta. Sendo assim, a realização de ações extensionistas revela a preocupação da Universidade em aproximar-se da sociedade, fortalecer suas relações, assim como objetiva despertar na comunidade o interesse e a prática do conhecimento para o auto cuidado (RESENDE et al, 2019).

Em odontologia, ainda é comum crianças e adolescentes não possuírem uma frequência adequada de consultas no dentista ou mesmo nunca terem frequentado o dentista. $\mathrm{O}$ desfecho mais encontrado nesse grupo é a cárie dentária, ainda considerada um agravo de saúde oral multifatorial, devido à sua prevalência e gravidade. A cárie dentária é considerada um grande problema para a saúde pública, além das doenças periodontais que ocorrem devido a deficiência na remoção mecânica do biofilme dentário e do uso regular do fio dental, resultando na calcificação da placa dentária e levando a um processo inflamatório dos tecidos gengivais (GREENSHILDS, 2019).

Nesse contexto, a educação em saúde e as estratégias de promoção de saúde bucal vêm para dar suporte a esses indivíduos jovens, na medida em que é o processo pelo qual constroem seus conhecimentos sobre a importância do cuidado oral, assim como também é promovido o desenvolvimento das habilidades necessárias para que eles possam atingir e manter a saúde bucal, e prevenir as doenças que são mais prevalentes nessa população (MACEDO, 2017).

As atividades extensionistas nos cursos de graduação em odontologia são uma oportunidade de promover educação em saúde. Diante do exposto, o objetivo deste trabalho é relatar a experiência de acadêmicas em uma disciplina extensionista do curso de odontologia da Universidade Franciscana-Santa Maria/RS durante a retomada das atividades práticas na pandemia da COVID-19.

\section{METODOLOGIA}

A metodologia utilizada nesta disciplina extensionista foi a Espiral Construtivista, proposta por Lima (2017), uma metodologia ativa de ensino-aprendizado que consiste em identificar os problemas, elaborar a questão problema, traçar objetivos, estabelecer hipóteses de explicação ou solução e aplicar à realidade. Este estudo é descritivo, do tipo relato de experiência e foi realizado a partir da vivência de acadêmicas na disciplina de Ações Integradas em Odontologia III do curso de Odontologia da Universidade Franciscana - UFN, ofertada aos estudantes do $7^{\circ}$ semestre da graduação.

A disciplina visa, através de atividades extensionistas, desenvolver habilidades e competências nos acadêmicos acerca de saúde bucal infantil, capacitando na realização de triagem de risco da doença cárie, além do refinamento de diagnósticos e execução de procedimentos preventivos e 
curativos em crianças e adolescentes participantes de projetos sociais da cidade de Santa Maria - RS. Para a comunidade envolvida espera-se que as ações possam restabelecer a saúde bucal e gerem um cuidado e uma conscientização maior em relação a sua saúde. Diminuindo assim a procura constante por procedimentos, para que ocorra a valorização do autocuidado.

As atividades de extensão relatadas neste estudo ocorreram de setembro a dezembro de 2020, durante o período de retomada das atividades práticas na pandemia da COVID-19. Como não era possível que os estudantes fossem até as comunidades, as crianças foram recebidas na Universidade Franciscana semanalmente no turno da tarde, elas eram trazidas pelo responsável do projeto social. Foram tomados todos os cuidados do protocolo de biossegurança e as atividades de educação em saúde eram realizadas em uma sala de aula com até duas crianças por vez. Nas clínicas também foi reduzido o número de crianças e cuidados foram tomados para minimizar a contaminação pela COVID-19. Durante os atendimentos clínicos foram realizados procedimentos de baixa a média complexidade, abordagens a respeito da higiene geral e bucal, adequação e mudanças dos hábitos alimentares em longo prazo e a propagação de informações de interesse das crianças e adolescentes a fim de promover o cuidado integrado.

\section{RESULTADOS E DISCUSSÃO}

Nos anos anteriores, os estudantes da disciplina de Ações Integradas em odontologia IIII se deslocavam até a comunidade, para ocorrer a aproximação com a realidade de cada criança, visto que a saúde bucal mantém uma relação direta às condições de moradia, alimentação, renda, trabalho, transporte, meio ambiente, lazer, liberdade, acesso a serviços de saúde e informação (BRASIL, 1990). Entretanto, tendo em vista o cenário da pandemia da COVID-19, algumas alterações no planejamento da disciplina foram necessárias, uma vez que a visita dos estudantes na comunidade não poderia ser realizada. Os encontros foram realizados nas Clínicas de Práticas Odontológicas da UFN, respeitando um criterioso protocolo de biossegurança. No primeiro contato entre os envolvidos, foram desenvolvidas estratégias de aproximação com cada paciente, baseado em acolhimento, observação dos determinantes sociais descritos anteriormente, e então a partir disso foram traçadas estratégias de tratamento e intervenção.

Após conhecer um pouco melhor e entender de que forma esses indivíduos vivem, como se relacionam e estabelecer as questões problemas, através de diálogo com o paciente e familiares quando presentes, propomos dentro de cada realidade soluções previamente planejadas. As necessidades estavam relacionadas principalmente a doença cárie e periodontal. Para cada paciente foi elaborado um plano de tratamento individualizado conforme suas necessidades, incluindo procedimento clínicos e preventivos, como por exemplo: raspagem supra gengival, restauração, exodontia, orientações de higiene bucal, fluorterapia e orientações de dieta, além de atividades individualizadas e coletivas de educação em saúde. 
Fato importante a se destacar era que para a maioria dos estudantes foi o primeiro contato com o paciente infantil, e no que se refere ao atendimento de crianças, é imprescindível o conhecimento do desenvolvimento biológico e intelectual. Também é importante o uso adequado de técnicas de manejo do paciente, como por exemplo, a que mais utilizamos, a técnica "Falar - Mostrar e Fazer", que visa estabelecer uma boa comunicação entre criança-dentista e consiste na explicação do procedimento de acordo com a idade de cada indivíduo, demonstração prévia dos materiais usados de forma visual, auditiva, oftálmica e tátil (MASSARA; REDUA 2013). Assim, os atendimentos foram em busca do conhecimento dos nossos pacientes em sua totalidade de forma que pudéssemos fornecer informações pregressas à criança bem como oferecer a interação com o ambiente a fim de diminuir os sentimentos de medo e ansiedade, e ao mesmo tempo aumentar a confiança. Com base no uso desta técnica conseguimos estabelecemos vínculo com o paciente.

A orientação de higiene bucal voltada para as especificidades de cada indivíduo, instruindo a escovação supervisionada a fim de condicionar o paciente, visto que a escovação é a forma mais utilizada, efetiva e socialmente aceita de higiene da cavidade oral. No entanto, para tornar-se eficaz no combate da placa bacteriana, é fundamental que a escovação seja orientada e supervisionada pelo profissional em algum momento de sua vida, sendo a motivação do paciente um fator essencial para melhores resultados (VALARELLI, 2011).

Como se sabe a dieta está diretamente relacionada com a saúde bucal, principalmente quando se refere a crianças, por esse motivo as ações foram desenvolvidas também com foco em discussões acerca de hábitos de alimentação saudável, buscando promover mudanças positivas no comportamento desses jovens que em grande parcela fazem ingestão de alimento cariogênico o que associado a uma higiene oral ineficiente e precária pode levar ao desenvolvimento de lesões de cárie e outras alterações dentárias. Algumas das abordagens se trataram da importância da redução no consumo de alimentos com alto teor de açúcares, da preferência por alimentos não processados, do encorajamento de maior consumo de frutas, legumes e verduras e da relação quantidade-qualidade-frequência de consumo.

Sendo assim, para que a troca entre profissional-paciente atingisse o meio externo, buscou-se desempenhar atividades informativas que fossem práticas, suficientes e ricas em informações de qualidade. Ao estimular bons hábitos, proporcionaríamos escolhas saudáveis que caminham juntas a garantia de uma saúde de qualidade e bem-estar, visto que problemas envolvendo a cavidade oral podem interferir de forma significativa tanto de modo pessoal como também social. Dessa forma, garantir os benefícios, explanar a importância do autocuidado ao longo da vida foram métodos pensados para que os assuntos abordados fossem memorizados e dispersados no meio onde vivem.

Em relação às atividades extensionistas educativas como complementação das estratégias estabelecidas, foram elaborados folhetos informativos para serem entregues aos pacientes, com fontes de leitura adequadas, plastificado o que permitiria uma maior longevidade e possibilidade que o paciente levasse até seu local de higiene e que contemplavam pequenos textos de fácil entendimento e 
imagens ilustrativas. O material didático abordou assuntos básicos e essenciais como o passo a passo para o uso adequado do fio dental, a escovação, como realizar o autoexame extra e intra-oral, doenças a nível oral como a cárie dental, a gengivite e a periodontite e de que forma são prevenidas. Além desse material confeccionamos de forma individualizada e exclusiva para a idade de cada paciente, livretos com tarefas de fácil compreensão para que eles contemplassem com suas respostas após a leitura do folheto informativo recebido anteriormente.

A partir dos retornos e finalização dos atendimentos clínicos, foi planejado um momento que fosse divertido, descontraído e dinâmico com uma atividade coletiva de acordo com a faixa etária do grupo, com o propósito de pontuar algumas questões de saúde bucal, instigar a exposição de suas opiniões, bem como esclarecer qualquer dúvida que ainda poderia persistir após as consultas odontológicas. Esta atividade foi realizada em uma sala de aula da Universidade, com até duas crianças por vez. Foi proposto um jogo que consistiu em perguntas e respostas com a finalidade de relacionar conhecimentos adquiridos durante os atendimentos em consonância a era digital, visto que temos conhecimento que cada vez mais o acesso à celulares, computadores e no geral, a internet tem imersão na vida dos indivíduos mais cedo. Ocultar essa realidade, não faria sentido, visto que nosso maior compromisso é ser um meio para que a informação chegue aos pacientes de forma coesa e que seja acessível dentro das suas referidas realidades.

O jogo aplicado foi o Kahoot, "uma plataforma de aprendizado baseada em jogos, usada como tecnologia educacional em escolas e outras instituições de ensino. Seus jogos de aprendizado, "Kahoots", são testes de múltipla escolha que permitem a geração de usuários e podem ser acessados por meio de um navegador da Web ou do aplicativo kahoot. As crianças tinham tempo para escolher a resposta que seria dirigida a um dos estudantes que selecionava a opção no jogo. Sendo uma plataforma para jogar entre mais pessoas, o objetivo nessa atividade, é estimular o raciocínio de forma mais rápida de modo individual. Ao final, através das questões desenvolvidas foi verificado um retorno positivo e atingindo o objetivo das ações com as orientações de higiene, saúde e dieta. Ao longo do tempo foi observado que desempenhamos um papel fundamental na vida desses indivíduos.

\section{CONCLUSÃO}

A vivência nesta disciplina durante a pandemia da COVID-19 foi ao mesmo tempo uma oportunidade de aprendizado e uma experiência construtiva baseada em resiliência e humanização, de diálogos, construção de vínculo, possibilidade de trocas e nos permitiu ajudar a criança a devolver a autonomia do cuidado. Deste modo, essa vivência foi de extrema importância e fundamental para o nosso crescimento acadêmico e pessoal, uma vez que nos proporcionou o desenvolvimento de várias competências, reforçou o conceito de trabalho em equipe e nos permitiu identificar desafios, facilidades, descobertas na infância, reforçando a ideia de que somos responsáveis por levar conhecimento, mudar estilos de vida, ainda em fase inicial de crescimento. 


\section{REFERÊNCIAS}

BRASIL. Lei n ${ }^{\circ}$ 8.080. Dispõe sobre as condições para a promoção, proteção e recuperação da saúde, a organização e o funcionamento dos serviços correspondentes e dá outras providências. Diário Oficial da União, Brasília, DF, 20 Set 1990.

CASTRO, C. C. L. P. et al. Adaptação dos cirurgiões-dentistas frente à ameaça da covid-19. Brazilian Journal of Development, v. 6, n. 9, p. 64449-64459, 2020.

GREENSHILDS, S. Oral health care in children. British Journal of Nursing, v. 28, n. 15. p. 980-981, 2019.

LIMA, V. V. Espiral construtiva: uma metodologia ativa de ensino-aprendizagem. Rev. Interface, v. 21, n. 61 , p. $421-434,2017$.

MACEDO, L. R. et al. Promoção de saúde bucal para pré-escolares: relato de experiência. Rev. Ciênc. Ext. v. 13, n. 4, p. 128-139, 2017.

MASSARA, M. L.A; REDUA, P.C.B. Manual de referência para procedimentos clínicos em odontopediatria. 2. ed. Santos, 2013.

RESENDE, T.A.C. et al. Ações extensionistas em saúde bucal. Arq Odontol, Belo Horizonte, 55: e14, 2019.

VALARELLI, F. P. et al. Importância dos programas de educação e motivação para saúde bucal em escolas: relato de experiência. Rev. Odontologia Clínico-Científica, v. 10, n. 2, p. 173-176, 2011. 